\title{
Queuing Model For Effective Customer Service Delivery In The Banking Industry: A Study Of Union Bank PLC In Enugu Metropolis
}

\author{
Iroegbu Ngozi Franca ${ }^{1}$ Agu, Okoro $\mathrm{Agu}^{2}$ \\ 1 ngoziirogbu@yahoo.com. \\ Management, University of Nigeria, Enugu campus \\ 2don_okojombo@yahoo.com \\ Management, University of Nigeria, Enugu campus
}

\begin{abstract}
The study highlights the imperativeness of maintaining an effective customer service delivery by attacking the notorious problem of long queue in service industry especially in Union Bank Plc. The following were the objectives: to highlight the cause(s) of clumsy service delivery in this bank which is manifested in long queues, to ascertain the usefulness of queuing model in ameliorating this problem, To examine the effects of long queue and poor service delivery on the customers, To examine the measures put in place by the bank to ameliorate the problem of long queue, to ascertain the usefulness of supervision of the tellers and facilities in ensuring the efficiency and effectiveness service delivery. The paper adopted a survey method with questionnaire and oral interviews as instruments of getting the data. The analysis of the study was presented in simple percentage in a table. The population of the study was 118 for staff (Junior/senior) and the population of customers being infinite, a sample size was derived using Williams and Freud formula to get a total of 462 customers. The data collected were analyzed with descriptive statistics. The findings indicate that the long queue is caused by poor supervision of tellers and facilities. The long queue has caused a high rate of drop of their customers to other banks. The bank has tried to embark on many strategies to attack this problem but it came late after many customers had gone. The study concludes that customer satisfaction is of prime importance to any enterprise that wants to control a high share of the market for their products. As all banks sell the same products but each bank's competitive advantage is its strategy for the satisfaction of her customers. Constant long queue in any service industry is an impediment to the realization of this goal. Proper supervision of queuing model is a panacea to this problem. The study recommends the following: proper and adequate supervision of tellers to maximize their efforts and show case the need for extra service points. There should be a constant appraisal of the staff to expose the trainable and un-trainable ones amongst them. The trainable ones should be sent for training while non-trainable ones will be laid off. There should be a proper examination of facilities and network system to keep them functional. Finally there should be regular promotional programmes to create the needed awareness to the public, informing them of the bank's re-engineering of its system to attract them back to the bank.
\end{abstract}

\section{Indexing terms/Keywords}

Queuing, Customer Service ,Union Bank

\section{Academic Discipline And Sub-Disciplines}

Provide examples of relevant academic disciplines for this journal: E.g., History; Education; Sociology; Psychology; Cultural Studies;

\section{SUBJECT CLASSIFICATION}

E.g., Mathematics Subject Classification; Library of Congress Classification

\section{TYPE (METHOD/APPROACH)}

Provide examples of relevant research types, methods, and approaches for this field: E.g., Historical Inquiry; QuasiExperimental; Literary Analysis; Survey/Interview.

\section{Council for Innovative Research}

Peer Review Research Publishing System

Journal: International Journal of Management \& Information Technology

Vol. 7, No. 3

editor@cirworld.com

www.cirworld.com, member.cirworld.com 


\section{INTRODUCTION}

Effective customer service delivery has remained a catalyst for the achievement of organizational goals of any enterprise. This is because there is a symbiotic relationship between customer satisfaction and his patronage, which will lead to the attainment of the organizational goal

It is when a customer is satisfied and is retained, that other prospective customers are attracted to the organization, this brings about the expected high profit. According to Noori et al (1995) customers; satisfaction leads to customer loyalty which according to recent studies is crucial to long term profitability. Loyal customers spend more, refer new clients to the firm.

Buttressing this fact, Albracht, (2008) observes that a growing number of organizations are giving increased attention to customer service. Financial institutions, hospitals, public utilities, airlines, retail stores, restaurants, manufacturers, wholesalers, etc, face the problem of securing and retaining the patronage of customers. Building long-term relationship with customers has been given a high priority by the majority of America's most successful enterprises.

Further to this, Fitzsimmons (2004) opines that "Ensuring that customers get what they want is called "a service quality and managing service delivery is the single most effective means of differentiation among companies. Technologies and travel industry development bring people and products even closer; therefore, service operations managers should make increasing customer participation in quality service delivery a major goal if they want to stay competitive in the market".

Bateson (1985) agrees with the above in his philosophy of "marketing concept" which he says is a shift of emphasis from product orientation to customer orientation, where employees of any organization see customer satisfaction as of prime importance.

Virtually all service-oriented organizations are plagued with long queues, even with the introduction of gadgets that quicken service.

According to Kotler (1999), when customers wait in queues, there is the danger that waiting time will become excessive, leading to the loss of some customers to competitors. In Hillier (2000), findings show that the number of hours the citizens of USSR waste waiting in queues to purchase basic necessities and Americans waste in a year in a queue can amount to 20 million person-year of useful work.

Queuing model has been seen as a veritable model to attack this notorious state. Mayhaw, Les, Smith, David (December 2006) see it as a mathematical study of waiting line which enables mathematical analysis of several related processes including: arrival at the back of the queue, waiting in the queue (essentially, a storage process) and being served by the server(s) at the front of the queue.

The theory permits the derivation and calculation of several performance measures, including: the average waiting time in the queue or the system, the expected number of waiting or receiving service and the probability of encountering the system in certain states such as empty, full or having to wait a certain time to be served (Tijmns, 2003).

Queuing analysis is to offer a reasonably satisfactory service to waiting customers, though not an optimization technique but it determines the measure of performance of waiting lines such as the average waiting time in the queue and the productivity of the service facility which can then be used to design the service installation .TAHA. (2008).

Seeing the danger of losing some customers to competitors because of long queues, many researchers have proposed increasing the number of service points, which is an increase in cost to the management. There is the need to strike a balance between the cost of losing customers to competitors due to long queues and the cost of providing extra facilities. It is observed that mere creation of extra facilities have always produced idle time for those facilities when there is no more queue. There is need to examine the extent to which monitoring and supervising of the operations of the tellers and the facilities in the area of time management, and the efficiency and effectiveness of the system, will help. It is against this background that this study seeks to find ways of ameliorating this problem.

\section{Statement of Problem}

Banking industry sells the same products but each banks competitive advantage hinges on her strategies for customer satisfaction which manifest in effective customer service delivery.

Union Bank Plc, a formidable bank, treats this customers' satisfaction with levity, hence, the unbearable long queue a customer is subjected to for transaction with them. To customers, banking with this bank is a nightmare; this state has led to a serious drop in their customer patronage to other competing banks. Some researchers have suggested increasing the service points (facilities) to reduce the long queue, but this portends a high cost for the management during idle time of the facilities. There is need to strike a balance between the cost of loosing the customers to competitors and the provision of extra facilities.

This situation appears complex and this study seeks ways of proffering the appropriate panacea to the problem.

\section{Objectives of the Study}

The study has the following objectives:

1. To highlight the cause(s) of clumsy service delivery in this bank which is manifested in long queues. 
2. To ascertain the usefulness of queuing model in ameliorating this problem.

3. To examine the effect of long queue and poor service delivery on the customers.

4. To examine measures put in place by the bank to ameliorate the problems of long queue.

5. To ascertain the usefulness of supervision of the tellers and facilities in ensuring the efficiency and effectiveness of service delivery.

\section{Research Questions}

1. What are the causes of long queue a customer is faced with to transact with the bank?

2. What is the usefulness of queuing model in ameliorating this problem?

3. How have the customers manifested their dissatisfaction with the poor customer service delivery they encounter in this bank?

4. What measures are put in place by the bank to ameliorate this notorious state?

5. What is the place of supervision in ensuring efficiency and effectiveness of the facilities and tellers?

\section{THEORETICAL FRAMEWORK}

\section{Agner Krarup Erlang}

Queuing theory was first propounded by Agner Krarup Erlang a Danish engineer when he created a model to describe the Copenhagen telephone exchange. It's application has been in telecommunications, traffic engineering, computing and the design of factories, shops, offices and hospitals. The content included single queuing model; Application to telephony; Queuing networks (mean, field limits, fluid limits, heavy traffic/diffusion approximation; utilizations and role of poisson process, exponential distribution.

\section{Little's theorem on queuing.}

Little's Theorem on Queuing states that the average number of customer $(\mathrm{N})$ can be determined from the following equation $\mathrm{N}=\lambda \mathrm{T}$.

Here lambda $\lambda$ is the average customers arrival rate and $T$ is the average service time for a customer.

He gave example with a restaurant where the customers' arrival rate (Lambda) doubles but the customers still spend the same amount of time in the restaurant $(T)$. This will double the number of customers in the restaurant $(N)$ By he same logic if the customer arrival rate remains the same but the customer service time doubles, this will also double total number of customers in the restaurant. (http://www.Littles-law.com/tag/queueing-theory accessed 23rd November, 2012).

\section{Greenshield's Model On Traffic Flow}

Greenshield's model was developed to aid an understanding of uninterrupted flow of traffic, unfortunately, Greenshield's model was unable to cope with the added complexities that were generated under uninterrupted flow conditions. Uninterrupted flow requires an understanding of queuing theory which is an entirely separate model of traffic flow.

(http://www,webl.uidaho.edu/niatt labmanual/chapters/trafficflowtheory/theoryandconcepts/Queuingtheory.htm. accessed. on 23rd November 2012).

\section{LITERATURE REVIEW}

The literature review will be done under the following headings:

i. The usefulness of effective customer service delivery in service industry.

ii. The problems of excessive waiting line for customer service delivery

iii. Classification of queuing system

iv. Characteristics of waiting line system
a) Structure
b) Arrival process
c) Queuing decision
d) Service organization

v. Features of a simple queue and multiple serve system

vi. Monitoring and supervision of queuing model

\section{The Usefulness Of Effective Customer Service Delivery In Service Industry}

The analysis of the need for effective customer service delivery shows that you can offer promotions and slash prices to bring in as many new customers as you can or want, but, unless you can get some of these customers to come back, your business would not be profitable for long. Good customer service is all about bringing customers back and sending them away happy-happy enough to pass positive feedback about your business along to others, who may 
then try the product or service you offer for themselves and in turn, become repeat customers. (Customer service compete analysis of web customer service tools www.Internet evolution.com.) accessed 3/2/2011.

According to Fitzsimons (2004). Ensuring that customers get what they want is called "service quality", managing service delivery is the single most effective means for differentiation among companies. Technologies and travel industry development bring people and product even closer. Service operations managers should make increasing customer participation in quality service delivery a major goal if they want to stay competitive in the market.

Further to the above, Bateson (1985) opines that today's emphasis on customers satisfaction which can be traced to a managerial philosophy that has been described as the "marketing concept", springs from the belief that the firm should dedicate all its policies, plans and operations to the satisfaction of the customers. This philosophy leaves no doubt in the minds of every employee that customer satisfaction is of prime importance.

Again, in agreement, Kaiwasaki (1999) states that we have entered the age of boundless competition, triggered in large part by an expanding global economy; multinational competition has increased dramatically in recent years and this means, a one-world market exists for products ranging from cars to computers. To compete successfully in markets where products are the same or very similar and prices are basically the same, service is often the only competitive advantage available.

\section{The Problems Of Excessive Waiting Line To Customer Service Delivery}

Many service-oriented organizations are usually plagued with the problems of long queues in the delivery of products to customers. Hillier (2000:25) observes that people have become accustomed to considerable amounts of waiting, but still get annoyed by unusually long waits. Having to wait is not just a petty personal annoyance, the amount of time a nation's populace wastes by waiting in queues is a major factor in both the quality of life there and the efficiency of the economy. For example, before its dissolution, the USSR was notorious for the tremendous long queues that its citizens frequently had to endure just to purchase basic necessities. Even in the United States today, it has been estimated that Americans spend 37,000,000 hours per year waiting in queues. If this time could be spent productively instead, it would amount to nearly 20 million person-year of useful work..

He further states that, even the staggering figures do not tell this whole story of the impact of excessive waiting line, gross inefficiencies also occur because of other kinds of waiting, than people standing in line, for example, making machines wait to be repaired may result in loss of production, vehicles (including ships and trucks that need to wait to be unloaded may delay subsequent shipments), Airplanes waiting to take off or land may disrupt travel schedules. Delays in telecommunication transmissions due to saturated lines may cause data glitches, manufacturing jobs to wait to be performed, may disrupt subsequent production. Delaying service jobs beyond their due dates may result in loss of future businesses (lbid).

Winston, et al (2001) stress that long waiting lines in service organizations can be bad for business and the money spent to reduce these lines is often money well spent. This is because, according to Kottler (1999), when customers wait in queues, there is the danger that waiting time will become excessive, leading to the loss of some customers to competitors. Kelly (2001) observes that few facilities produce bottleneck which manifest as queues and customers are not interested in waiting.

Egolium, (2001) supports the above by saying that long queues at business service points mean that customers are being delayed, this may be due to poor rate of service which usually dissatisfies the customers. With such dissatisfaction, many present and potential customers shy away from patronizing the business organization and move elsewhere for better and faster service.

\section{Uses of Queuing Model}

Further to this, TAHA (2008) observes that queuing model analysis is to offer a reasonable satisfactory service to waiting customers by checking the waiting time and productivity of the service facilities; which can be used to design the service installation.

\section{Need For Balance}

Although the length of queue at service points in an organization can be considerably reduced by increasing the capacity of the service facilities, this will be at excessive costs. The costs are in terms of personnel, equipment and spaces. There is, therefore need to maintain a kind of economic balance between the cost of service and the cost associated with customers waiting in queues for the service (Egolum, 2001).

\section{The Queuing Theory And Its Classification}

The queuing theory is a branch of operations research that is also known as stochastic; it is to study the object of a service request generated by randomness of meeting and separation phenomenon theory. Queuing theory problem was first extracted from the telecommunication outlet. In latter development, queuing theory has been applied to transportation, computer system, public services and other areas (Tijims, 2003).

A queue is formally defined as consisting of a server and a waiting line for customers, needing service at the server. Each customer joins the line at the end of the waiting line. As customers at the front of the line are served, those behind gradually move to the head of the line. A customer leaves as soon as he has received his service requirement 
from the server and the server begins to serve the next customer in line. (Mhtml: file://c:Documents/Adminstrator, extracted on 7/2/2011).

\section{The Basic Queuing Structure}

The structure means that the customer requiring service arrives from his base to the service point only to meet others who are already waiting to be attended to, he joins the waiting line (queue) pending the time he is selected for service. Structure also, is the arrival of customers from different sources who join the waiting line (queue), selection of a customer from the queue for service, the service mechanism and the departure of the served customer.

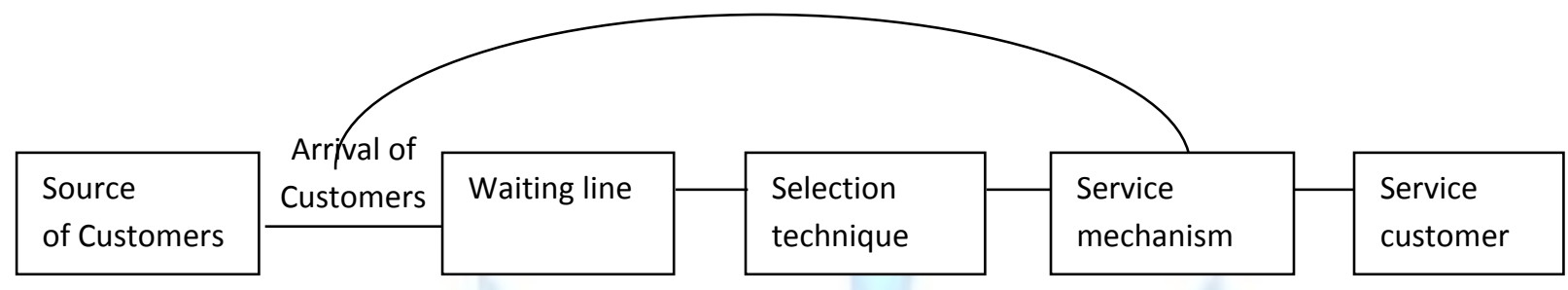

Figure 1: Source: Egollum C. C. (2001) Quantitative Techniques for Management Decision. Enugu Nigeria. Snapp Press Ltd.

\section{QUEUING COMPONENTS}

In the diagram above the queuing components are as follows (Egolum 2001).

\section{The Calling Population}
a. The calling population
b. Arrival process
c. Queuing discipline

The source of customers otherwise called the "calling population" comprises all potential customers that may require service at one time or another. The size may be finite or infinite.

FINITE

In a finite population model, there is a fixed number $\mathrm{N}$, of jobs, jobs arrive at the queue from some source and after completing their service requirement, they will retire to this source. If there are $\mathrm{K}$-jobs in the queue, there are $\mathrm{N}$-K jobs in the source. We will assume that jobs that are in the source are exponentially distributed in the amount of time, in average before returning to the queue and they are independent of each other.

\section{Infinite population}

The size of the source population may be unlimited (infinite) when the number of arrivals at a given time is just a small portion of the potential arrival or limited (finite) when the population size is relatively known (Olaninyi 2004).

\section{Arrival Process}

This refers to the manner in which customers desiring service get to the service system. The characteristics of this process differ in form and composition. It can be either arrival in batches, individually or both. This form of arrival is discrete. The pattern of arrival at the system is considered random when arrivals are independent of one another and their occurrence cannot be predicted exactly. Also the number of arrivals per unit of time in queuing problems can be estimated by a Poisson probability distribution. The service time distribution may be constant when it takes the same amount of time to take care of each customer or random when the reverse holds. If arrival rate is Poisson distributed, a negative exponential probability distribution is assured for random service times.

The mean value of the arrival rate is represented by $\lambda$ and the service rate is randomly distributed according to exponential distribution and the mean value of service is represented by $\mu$.

\section{QUEUING DISCIPLINE}

This refers to the priority rule by which customers are served, that is, the order in which items received service. According to Jay and Barry (1993), there are two main categories; they include:

i. Pre-emptive priority: This is common in emergency situations which allow customers that arrive at anytime to replace customers that are being served; for example, in-patient treatment in hospitals.

ii. Non pre-emptive priority: Here, items in the queue are arranged so that the item with the highest priority in the system is served first and there is no displacement of items in service. Times method include:

a. FIFO (First in-first out): Allows the first item to enter the system (items at the head of the queue) to be served first. It is the most frequently applied discipline because it is believed to be fairer than the other types of rules.

b. LIFO (Last-in-first out): Here, the last item on the queue or that which entered the system last is served first.

c. RANDOM AND PRIORITY: Priority occurs when an arriving customer is chosen for service ahead of some other customers already in the queue GUPTA and HIRA (2005). The principle also serves customers one at a time. However, the customer with the shortest waiting time will be served first $(a, b, c, d, e, f$, Pettinen AS; chapter 8 queuing systems lecturer notes 5-38, 145, introduction to Tele-traffic theory). 
Changing the queue discipline (the rule by which we select the next customer to be served) can often reduce congestions. The queue discipline "choose the customer with the lowest service time" results in the smallest value for the time (on average) a customer spends queuing.

Queuing Characteristics

1.Balking (customers deciding not to remain in the queue

2. Reneging (customers on seeing the long queue decide not to join the queue at all).

3. Jockeying (customers switching between the queues if they think they will get served faster by doing so.

\section{OPERATING CHARACTERISTICS OF WAITING LINE MODEL}

According to Anderson et al, (2010), waiting line model consists of mathematical formulas and relationships that can be used to determine the operating characteristics performance measured for a waiting line. The operating characteristics of interest include the following:-

1. The probability that no units are in the system or the system is empty

2. The average number of units in the waiting line

$$
P_{0}=1-\frac{\lambda}{\mu}
$$

$$
L_{q}=\frac{\lambda^{2}}{\mu(\mu-\lambda)}
$$

3. The average number of units in the system (number of units in the waiting line) plus the number of units being served.
$L=L_{q}+\frac{\lambda}{\mu}$
4. The average time a unit spends in the waiting line

$$
W_{q}=\frac{L_{q}}{\lambda}
$$
5. The average time a unit spends in the system (the waiting time of the service time)

$$
W_{q}=W_{q}+\frac{\lambda}{\mu}
$$
6. The probability that an arriving unit has to wait for service.
7. The probability of units in the system

$$
P_{n}=\left[\frac{\lambda}{\mu}\right] P_{0}
$$

They further observe that managers who have such information are better able to make decisions that balance desirable service level against the cost of providing the service.

In their findings on the "queuing model in Action" they observed how this model helped to determine the number of automatic teller machines (ATM) to be placed at New York City Banking Centre, waiting line model promoted the creation of new kind of line and chief line director to implement first-come, first-served queue discipline at whole foods market in the Cherlsea neighborhood of New York City and in New Haven.

\section{Monitoring And Supervising Queuing Model}

The need to monitor and supervise the system is being given by Wang et al (2007) in his forecasting the net-work traffic using Queuing theory. According to them the network traffic is very common, It is worse when the traffic comes under extreme situation, it will lead to the nets paralysis therefore monitoring the routor data disposal function used in the network becomes the way to satisfy the markov process. The network traffic monitoring model which is tested, experimented and analyzed by the actual system shows that using the Queuing theory will optimize the network traffic, it is convenient and simple for calculating and monitoring the network traffic properly.

\section{Materials And Methods}

The paper adopted a survey method designed to meet the objectives of the study. The primary data were obtained through the administration of questionnaire, oral interviews to both staff and customers of the bank and observation of the on-going activities in the bank while the secondary data were collected through critical exposition of available books, journals and internet materials.

The analyses of the data were done by simple percentage arranged in tables.

\section{POPULATION}

The population of this study was in two forms: staff and customers of the bank. The number of the staff, both permanent and outsourced (Senior/Junior) was 118. This is shown in the table below:-

Table 1: Staff of Union Bank PIc in Enugu Metropolis

\begin{tabular}{|c|c|c|c|}
\hline Branches & Permanent staff & Outsourced & Total \\
\hline Garden Avenue & 27 & 13 & 40 \\
\hline
\end{tabular}




\begin{tabular}{|l|c|c|c|}
\hline $1^{\text {st }}$ Okpara Avenue & 14 & 5 & 19 \\
\hline $2^{\text {nd }}$ Okpara Avenue & 9 & 5 & 14 \\
\hline Ogui Road & 16 & 7 & 23 \\
\hline Ogbete Market & 8 & 6 & 14 \\
\hline Ziks Avenue & 6 & 2 & 8 \\
\hline Total & $\mathbf{8 0}$ & $\mathbf{3 8}$ & $\mathbf{1 1 8}$ \\
\hline
\end{tabular}

Source: Bank Information, 2011.

The population of customers is infinite and the researcher adopted Freud and Williams formula as cited in Nwabuoku (2001) to determine the sample size for each branch of the bank as shown in Appendix A below.

\section{SAMPLE SIZE}

The population of the staff of the bank was small the researcher decided to use all so the staff sample size was exhaustive. The population of the customers is infinite, to get the sample size, the study adopted Freud and Williams formula as cited in Nwabuoku (2001) to determine the sample size for each branch as shown in Appendix A below. The sample size of customers of each branch was summed up as follows:

Table 2: Each Banks Customer Size

\begin{tabular}{|l|c|c|c|}
\hline \multicolumn{1}{|c|}{ Branches } & \multicolumn{3}{c|}{ Total no of sample Population } \\
\hline Ogui Road (OR) & 138 & 128 & 10 \\
\hline $1^{\text {st }}$ Okpara Avenue (OA) & 73 & 67 & 6 \\
\hline Ziks Avenue (ZA) & 45 & 40 & 5 \\
\hline Ogbete Market (OA) & 30 & 27 & 3 \\
\hline $2^{\text {nd }}$ Okpara Avenue $\left(\mathrm{OA}^{2}\right)$ & 30 & 26 & 4 \\
\hline Garden Avenue (GA) & 146 & 132 & 14 \\
\hline & $\mathbf{4 6 2}$ & $\mathbf{4 2 0}$ & $\mathbf{4 2}$ \\
\hline
\end{tabular}

Source: Union Bank Office

DATA PRESENTATION AND ANALYSIS FOR STAFF

Table 3: How many tellers are in the front office attending to customers?

\begin{tabular}{|l|l|}
\hline Branches & Tellers Respondents \\
\hline Garden Avenue (GA) & 8 \\
\hline Okpara Avenue (OA) & 5 \\
\hline Ogui Road (OR) & 7 \\
\hline Ogbete Market (OM) & 5 \\
\hline $2^{\text {nd }}$ Okpara Avenue (OA) & 6 \\
\hline Ziks Avenue (ZA) & 3 \\
\hline
\end{tabular}

\section{Source: Union Bank Office}

Table 3, 23(21\%) of the respondents are of the opinion that tellers are supervised during operations while $87(79 \%)$ said that they are not supervised during operations.

Table 4: Cause of a long queue a customer faces to have transaction

\begin{tabular}{|l|c|c|c|c|c|c|c|c|}
\hline \multicolumn{1}{|c|}{ Options } & GA & OA $^{\text {15t }}$ & OA $^{\text {2nd }}$ & OR & OM & ZA & Freq & $\%$ \\
\hline Poor supervision & 15 & 8 & 7 & 11 & 6 & 5 & 52 & 47 \\
\hline $\begin{array}{l}\text { Poor knowledge of the tellers in } \\
\text { the use of modern gadgets }\end{array}$ & 9 & 4 & 3 & 5 & 3 & 1 & 25 & 23 \\
\hline Seasonal influx of customers & 3 & 2 & 1 & 2 & 2 & 1 & 11 & 10 \\
\hline Constant network failure & 9 & 4 & 2 & 3 & 3 & 1 & 22 & 20 \\
\hline$\quad$ Total & $\mathbf{3 6}$ & $\mathbf{1 8}$ & $\mathbf{1 3}$ & $\mathbf{2 1}$ & $\mathbf{1 4}$ & $\mathbf{8}$ & $\mathbf{1 1 0}$ & $\mathbf{1 0 0}$ \\
\hline
\end{tabular}

Source: Field Work 2010.

Table 4 reveals that $52(47 \%)$ of the respondents said that poor supervision of tellers is usually the cause of long queue in the bank, this is because tellers may have undue delay in their service to the customers. 25(23\%) are of the opinion that it is poor knowledge of the use of modern gadgets by the tellers where as $11(10 \%)$ of the respondents said it is the seasonal influx of customers like during payment of salaries or any of such occasion, while $22(20 \%)$ said it is constant network failure. The percentage .for poor supervision still tops the list because if there was proper supervision the other problems will be seen and managed.

Table 5 Experiencing any form of balking or reneging of customers from the long queue.

\begin{tabular}{|l|c|c|c|c|c|c|c|c|}
\hline \multicolumn{1}{|c|}{ Options } & GA & OA $^{\text {Ist }}$ & OA $^{\text {2nd }}$ & OR & OM & ZA & Freq & $\%$ \\
\hline Often & 12 & 6 & 3 & 10 & 8 & 6 & 45 & 41 \\
\hline Very often & 19 & 9 & 8 & 7 & 4 & 1 & 48 & 44 \\
\hline Not often & 5 & 3 & 2 & 4 & 2 & 1 & 17 & 15 \\
\hline Total & $\mathbf{3 6}$ & $\mathbf{1 8}$ & $\mathbf{1 3}$ & $\mathbf{2 1}$ & $\mathbf{1 4}$ & $\mathbf{8}$ & $\mathbf{1 1 0}$ & $\mathbf{1 0 0}$ \\
\hline
\end{tabular}

Source: Field Work 2010. 
Table 5 shows that $45(41 \%)$ and $48(44 \%)$ of the respondents agree that there is usually reneging or balking of customers from the long queue while only $17(15 \%)$ of the respondents said it does not happen. The implication is that many who are tired or afraid of the long queue do not wish to remain with the bank.

Table 6: The Banks share of patronage

\begin{tabular}{|c|c|c|c|c|c|c|c|c|}
\hline Options & GA & $\mathrm{OA}^{1 \mathrm{st}}$ & $\mathrm{OA}^{2 \mathrm{nd}}$ & OR & OM & ZA & Freq & $\%$ \\
\hline $5 \%$ & 6 & 3 & 2 & 10 & 7 & 1 & 29 & 26 \\
\hline $10 \%$ & 10 & 5 & 3 & 2 & 2 & 4 & 26 & 24 \\
\hline $20 \%$ & 15 & 5 & 6 & 5 & 1 & 2 & 34 & 31 \\
\hline Above $2 \%$ & 5 & 5 & 2 & 4 & 4 & 1 & 21 & 19 \\
\hline Total & 36 & 18 & 13 & 21 & 14 & 8 & 110 & 100 \\
\hline
\end{tabular}

Source: Field Work 2010.

The above table has the following information $29(26 \%)$ of the respondents said $5 \%, 26(24 \%)$ said it is $10 \%$, where as $34(31 \%)$ of the respondents said it is $20 \%$ and $21(19 \%)$ said it is above $20 \%$. The respondents views are scattered which is an indication that they are trying to protect the image of their bank. Their answers are not consistent with what is happening in their bank.

Table 7: Are Customers satisfied with your service

\begin{tabular}{|l|c|c|c|c|c|c|c|c|}
\hline \multicolumn{1}{|c|}{ Options } & GA & $\mathbf{O A}^{\text {1st }}$ & $\mathbf{O A}^{\text {2nd }}$ & OR & OM & ZA & Freq & $\%$ \\
\hline Yes & 6 & 8 & 7 & 8 & 6 & 4 & 39 & 35 \\
\hline No & 20 & 6 & 3 & 11 & 5 & 3 & 48 & 44 \\
\hline Indifferent & 10 & 4 & 3 & 2 & 3 & 1 & 23 & 21 \\
\hline Total & $\mathbf{3 6}$ & $\mathbf{1 8}$ & $\mathbf{1 3}$ & $\mathbf{2 1}$ & $\mathbf{1 4}$ & $\mathbf{8}$ & $\mathbf{1 1 0}$ & $\mathbf{1 0 0}$ \\
\hline
\end{tabular}

Source: Field Work 2010.

Table 7 reveals that $39(35 \%)$ of the respondents said Yes that customers are satisfied with their service while $48(44 \%)$ said No that they are not satisfied where as $23(21 \%)$ are indifferent to the question.

Table 8: Causes of drop rate in patronage of customers over 5 years

\begin{tabular}{|l|c|c|c|c|c|c|c|c|}
\hline \multicolumn{1}{|c|}{ Options } & GA & $\mathbf{O A}^{\mathbf{1 5 t}}$ & $\mathbf{O A}^{\text {2nd }}$ & OR & OM & ZA & Freq & $\%$ \\
\hline Long queue & 12 & 8 & 7 & 11 & 8 & 4 & 50 & 45 \\
\hline Un conducive environment & 6 & 3 & 2 & 2 & 1 & 1 & 15 & 14 \\
\hline Delay in service delivery & 10 & 5 & 3 & 6 & 3 & 2 & 29 & 26 \\
\hline Poor PR of tellers & 8 & 2 & 1 & 2 & 2 & 1 & 16 & 15 \\
\hline Total & $\mathbf{3 6}$ & $\mathbf{1 8}$ & $\mathbf{1 3}$ & $\mathbf{2 1}$ & $\mathbf{1 4}$ & $\mathbf{8}$ & $\mathbf{1 1 0}$ & $\mathbf{1 0 0}$ \\
\hline
\end{tabular}

Source: Field Work 2010.

Table 8 reveals that $50(45 \%)$ of the respondents are of the opinion that the high rate of drop of customers from the bank over 5 years is caused by long queue, a customer suffers in the bank while un conducive environment takes $15(14 \%)$, delay in attending to customers takes $29(26 \%)$ and poor PR of tellers took $16(15 \%)$. This shows that the customers can manage any other problem but that of long queue is unbearable.

Table 9: Open to suggestion to fight this problem

\begin{tabular}{|c|c|c|c|c|c|c|c|c|}
\hline Options & GA & $\mathrm{OA}^{1 \mathrm{st}}$ & $\mathrm{OA}^{2 \mathrm{nd}}$ & OR & OM & ZA & Freq & $\%$ \\
\hline Yes & 30 & 11 & 10 & 19 & 12 & 7 & 89 & 81 \\
\hline & 6 & 7 & 3 & 2 & 2 & 1 & 21 & 19 \\
\hline Total & 36 & 18 & 13 & 21 & 14 & 8 & 110 & 100 \\
\hline
\end{tabular}

Source: Field Work 2010.

This table 9 reveals that $89(81 \%)$ of the respondents said that the bank is open to suggestions while only $21(19 \%)$ said no that means that the bank is open to suggestion.

Table 10: Maximum Time to Serve each Customer

\begin{tabular}{|l|c|c|c|c|c|c|c|c|}
\hline \multicolumn{1}{|c|}{ Options } & GA & OA $^{\text {15t }}$ & OA $^{\text {2nd }}$ & OR & OM & ZA & Freq & $\%$ \\
\hline 5mins & 14 & 8 & 10 & 14 & 7 & 4 & 57 & 52 \\
\hline 7mins & 9 & 5 & 1 & 5 & 4 & 2 & 26 & 24 \\
\hline 10mins & 8 & 4 & 1 & 1 & 2 & 1 & 17 & 15 \\
\hline Above 10mins & 5 & 1 & 1 & 1 & 1 & 1 & 10 & 9 \\
\hline \multicolumn{1}{|c|}{ Total } & $\mathbf{3 6}$ & $\mathbf{1 8}$ & $\mathbf{1 3}$ & $\mathbf{2 1}$ & $\mathbf{1 4}$ & $\mathbf{8}$ & $\mathbf{1 1 0}$ & $\mathbf{1 0 0}$ \\
\hline
\end{tabular}

Source: Field Work 2010.

Table 10 shows that $57(52 \%)$ of the respondents said that the maximum time given to them is $5 \mathrm{mins}$ to attend to customers, $26(24 \%)$ of the respondents said $7 \mathrm{mins}, 17(15 \%)$ of the respondents said it is $10 \mathrm{mins}$ while $10(9 \%)$ of the respondents said above 10mins.

Table 11: Are Tellers Supervised during operation

\begin{tabular}{|l|c|c|c|c|c|c|c|c|}
\hline Options & GA & OA & OA $^{2}$ & OR & OM & ZA & Freq & $\%$ \\
\hline Yes & 9 & 3 & 4 & 2 & 3 & 2 & 23 & $21^{0}$ \\
\hline No & 27 & 15 & 9 & 19 & 11 & 6 & 87 & 79 \\
\hline Total & $\mathbf{3 6}$ & $\mathbf{1 8}$ & $\mathbf{1 3}$ & $\mathbf{2 1}$ & $\mathbf{1 4}$ & $\mathbf{8}$ & $\mathbf{1 1 0}$ & $\mathbf{1 0 0}$ \\
\hline
\end{tabular}


Source: Field Work 2010.

\section{FOR CUSTOMERS}

\section{Question 1}

Table 12: Years of banking with UNB PIc

\begin{tabular}{|l|c|c|c|c|c|c|c|c|}
\hline \multicolumn{1}{|c|}{ Options } & GA & OA $^{\text {1st }}$ & OA $^{\text {2nd }}$ & OR & OM & ZA & Freq & $\%$ \\
\hline 5 years & 12 & 5 & 11 & 2 & 2 & 10 & 42 & 10 \\
\hline 10 years & 15 & 13 & 29 & 5 & 6 & 24 & 92 & 22 \\
\hline 20 years & 34 & 20 & - & 9 & 7 & 40 & 110 & 26 \\
\hline Above 20 years & 67 & 29 & - & 11 & 11 & 58 & 176 & 42 \\
\hline \multicolumn{1}{|c|}{ Total } & $\mathbf{3 6}$ & $\mathbf{1 8}$ & $\mathbf{1 3}$ & $\mathbf{2 1}$ & $\mathbf{1 4}$ & $\mathbf{8}$ & $\mathbf{1 1 0}$ & $\mathbf{1 0 0}$ \\
\hline
\end{tabular}

Source: Field Work 2010.

From the above table, out of 420 respondents, $42(10 \%)$ indicated 5 years, $92(22 \%)$ indicated 10 years, $110(26 \%) 20$ years and $176(42 \%)$ of above 20 years of banking with this bank. This indicates that this bank has a tract history of being great and formidable.

\section{Question 2}

Table 13: Rating their service delivery

\begin{tabular}{|l|c|c|c|c|c|c|c|c|}
\hline \multicolumn{1}{|c|}{ Options } & GA & OA $^{\mathbf{1 S t}}$ & $\mathbf{O A}^{\text {2nd }}$ & OR & OM & ZA & Freq & $\%$ \\
\hline Good & 10 & 5 & 7 & 5 & 6 & 30 & 63 & 15 \\
\hline Very good & 5 & 2 & 1 & 2 & 2 & 20 & 32 & 8 \\
\hline Poor & 45 & 21 & 12 & 8 & 7 & 39 & 132 & 31 \\
\hline V. Poor & 68 & 39 & 20 & 12 & 11 & 43 & 193 & 46 \\
\hline \multicolumn{1}{|c|}{ Total } & $\mathbf{3 6}$ & $\mathbf{1 8}$ & $\mathbf{1 3}$ & $\mathbf{2 1}$ & $\mathbf{1 4}$ & $\mathbf{8}$ & $\mathbf{1 1 0}$ & $\mathbf{1 0 0}$ \\
\hline
\end{tabular}

Source: Field Work 2010.

In the question of rating the service delivery of this bank, $63(15 \%)$ of the respondents said good, $32(8 \%)$ responded very good while $132(31 \%)$ said poor and $193(46 \%)$ indicated very poor. A total of $77 \%$ of the respondents do not like their service delivery.

\section{Question 3}

Table 14: Why they are still banking with the bank

\begin{tabular}{|l|c|c|c|c|c|c|c|c|}
\hline \multicolumn{1}{|c|}{ Options } & GA & $\mathbf{O A}^{\mathbf{1 s t}}$ & $\mathbf{O A}^{\text {2nd }}$ & OR & OM & ZA & Freq & $\%$ \\
\hline $\begin{array}{l}\text { Confidence in their asset } \\
\text { base }\end{array}$ & 35 & 40 & 10 & 10 & 7 & 60 & 162 & 39 \\
\hline Employers bank & 60 & 15 & 6 & 20 & 9 & 30 & 140 & 33 \\
\hline $\begin{array}{l}\text { International business } \\
\text { purpose }\end{array}$ & 33 & 12 & 10 & 10 & 11 & 42 & 118 & 28 \\
\hline \multicolumn{1}{|c|}{ Total } & $\mathbf{3 6}$ & $\mathbf{1 8}$ & $\mathbf{1 3}$ & $\mathbf{2 1}$ & $\mathbf{1 4}$ & $\mathbf{8}$ & $\mathbf{1 1 0}$ & $\mathbf{1 0 0}$ \\
\hline
\end{tabular}

Source: Field Work 2010.

From the above table, 162(39\%) of the respondents opined that the reason for banking with the bank inspite of their poor service delivery is their confidence in their Asset base while 140(33\%) said it is employers' bank and 118(28\%) is for international business purpose. This implies that though this bank's service delivery is poor yet they still have some customers that are there.

\section{Question 4}

Table 15: Ways of ameliorating this queuing problem in the bank

\begin{tabular}{|l|c|c|c|c|c|c|c|c|}
\hline \multicolumn{1}{|c|}{ Options } & GA & OA $^{\text {1st }}$ & OA $^{\text {2nd }}$ & OR & OM & ZA & Freq & $\%$ \\
\hline Increase the supervision of tellers & 48 & 25 & 9 & 10 & 15 & 60 & 167 & 40 \\
\hline Increase the number of tellers & 10 & 7 & 3 & 2 & 7 & 12 & 41 & 10 \\
\hline Train the tellers for modern operation & 36 & 15 & 9 & 7 & 8 & 36 & 111 & 26 \\
\hline $\begin{array}{l}\text { Functional facilities and constant } \\
\text { network service. }\end{array}$ & 34 & 20 & 5 & 8 & 10 & 24 & 101 & 24 \\
\hline \multicolumn{1}{|c|}{ Total } & $\mathbf{1 2 8}$ & $\mathbf{6 7}$ & $\mathbf{4 0}$ & $\mathbf{2 7}$ & $\mathbf{2 6}$ & $\mathbf{1 3 2}$ & $\mathbf{4 2 0}$ & $\mathbf{1 0 0}$ \\
\hline
\end{tabular}

Source: Field Work 2010.

The table above shows a total of $167(40 \%)$ of the respondents who support increasing the rate of supervision of tellers as a way of ameliorating the problem of queuing, $41(10 \%)$ said, increase the number of tellers, $111(26 \%)$ opines that the remedy is train the tellers in the use of modern gadgets while $101(24 \%)$ responded that if the gadgets are made functional and there is constant network service this problem will be solved. All these are possible solutions but supervision ranks high because it takes supervision to identify all these and act on time.

\section{FINDINGS}

The study made the following findings:

(1) The long queue that a customer faces in Union Bank Plc is caused by poor supervision of tellers and poor use of the modern facilities like computer etc. that hinder them from expediting action in their service delivery. 
The previous researchers suggested increasing the service points as a panacea to the long queue this is seen as a huge cost on the management because of the idle time that could occur. If there is adequate supervision, of the tellers, they will maximize the efforts of the existing tellers and if there is need for extra service point, it will be provided without idle time created.

An example of a well supervised banking activity.

\section{Question 1}

People arrive randomly at a bank teller at an average rate of 30 per hour , what are the average number of customers in the queue, if the teller takes an average of 0.5 minutes to serve each customer what happens if the average service time changes to $1.0 \mathrm{mins}, 1.5 \mathrm{mins}$ or $2.0 \mathrm{mins}$ ? What are the average time in the queue for each service time?.

\section{Solution}

The average arrival rate is $\lambda=30$, if the teller takes an average of $0.5 \mathrm{mins}$ to serve each customer, this is equivalent to a service rate of 120 per hour. Then the average number of customers in the queue excluding anyone being served

The average time in the queue is $\mathrm{w}_{\mathrm{q}}$

$$
L_{q}=\frac{\lambda^{2}}{\mu(\mu-\lambda)}=\frac{30^{2}}{120(120-30)}=0.083 \mathrm{hrs}
$$

$$
W_{q}=\frac{\lambda}{\mu(\mu-\lambda)}=\frac{30^{2}}{120(120-30)}=0.003 \mathrm{hrs}
$$

Similarly substituting $\mu=60$ and 40 (corresponding to average service time of one minute and 1.5 minutes respectively gives.

$$
\begin{gathered}
\mu=60 . L_{q}=0.5 W_{q}=0.017 \mathrm{hrs} \\
\mu=40 . L_{q}=2.25 W_{q}=0.075 \mathrm{hrs}
\end{gathered}
$$

If the average service time is raised to 2 minutes, the service rate is $\mu=30$. This does not satisfy the. condition that $\mu$ $>\lambda$ and the system will not settle down to a steady state.

To find the average number of people in the

Similarly the average time in the system is

$$
L=L_{q}+\frac{\lambda}{\mu}
$$

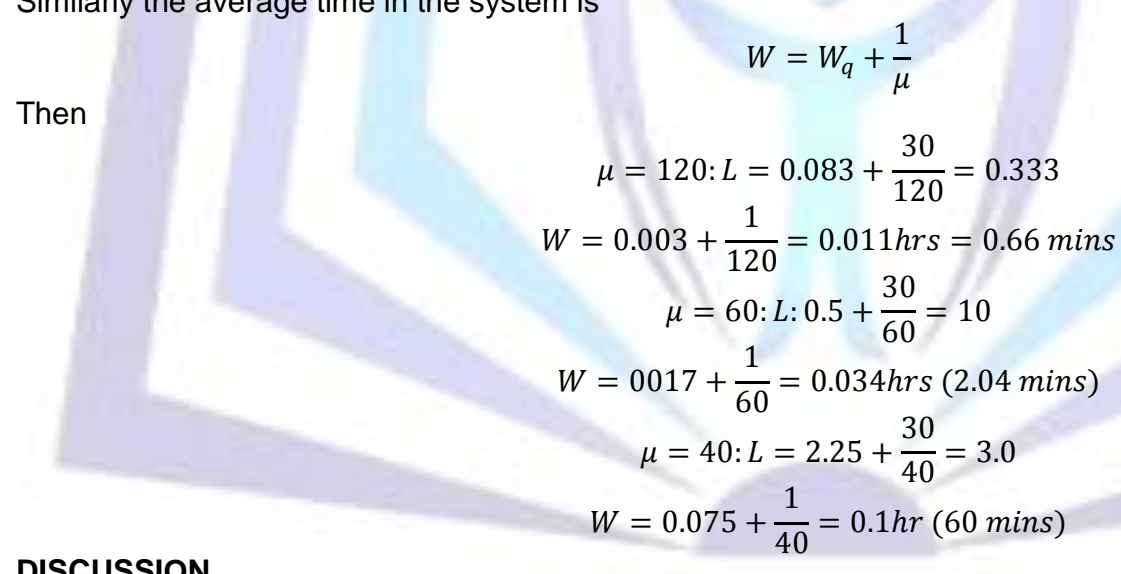

\section{DISCUSSION}

The above example shows that the changes that can take place in the queue stems from the time spent in attending to the customers. The right service time as stipulated by the bank can affect positively the long queue when the supervisor adequately monitors the activities of the tellers during operation ensuring that the service time is enforced.

1. Queuing model plays a significant role in presenting definite figures that will aid in decision making especially as it affects supervision of the operations.

2. The finding further shows that, the negative impact of this long queue and poor service delivery in this bank is grave. Many have reneged, balked from the long queue and finally left the bank. This is manifested in the high rate of drop in their customer patronage.

3. The study reveals that the bank has really embarked on serious strategies like the following to ameliorate this state:

a. "Turn around time of 5 mins". This is the maximum time a teller is expected to attend to customers within a given period. 
b. Showcasing the activities of the workers in the bank's website as "Horror fame or Horror shame for positive or negative activities respectively. This strategy will expose the evil doers and encourage the hard working staff.

c. They have also established the monitoring team. That visits their branches without notice or camouflaging to get the exact activities of the staff.

4. The study reveals that these strategies of the bank came late, after many of their customers have lost faith in them. The responses of the staff and customers show that supervision of the activities in the bank is the main ingredient needed for the bank to function well and come back to its past glory

\section{CONCLUSION}

It is obvious that no enterprise thrives well and achieves its goal without giving serious attention to the satisfaction of the customers. Banking industry sells the same product but each bank's competitive advantage is its strategy for the satisfaction of the customers. Constant long queue in any service industry is an impediment to the realization of this singular goal. Proper supervision of queuing model is a panacea to this problem.

\section{RECOMMENDATIONS}

The study recommends the following

1. Proper and adequate supervision of tellers to maximize their efforts, dictate when there is need for extra teller (service point) and when to reduce the number to avoid idle time for the service points which is a huge cost on the management.

2. There should be constant appraisal of the staff to get the trainable and non trainable ones. The non trainable ones should be laid off while the trainable ones are sent on training programmes to help them fit into the modern style of banking.

3. The facilities and the network system should be constantly examined so that they are kept functional to avoid distorting operations when they breakdown.

4. The implementation of those strategies the bank has put in place like the "Horror fame or horror shame" should be adequately monitored to ensure the realization of their goal.

5. There should be regular promotional programmes to create the needed awareness to the public of the re-engineering of the operational structure of the bank; this is to attract people back to the bank.

\section{REFERENCES}

[1] Abracht K., (2008). Service America: Doing Business in the New Economy http://www.amazon.com/karlAlbrecht/e/80027mmE3A/ref=utt athr 1 Accessed11-04-13.

[2] Bateson, T.S. and Snell, A. (2009). Management: Leading \& Collaborating in the Competitive World, 8 ed. Irwin, Mc Graw-Hills.

[3] Noori H., Russel R. (1995). Production and Operations Management: Total Quality and Responsiveness. India. McGraw-Hill Service in Management.

[4] Flood J. E. (1998). Telecommunication Switching Traffic and Networks: Telecommunications Traffic New York. Prentice-Hall.

[5] Hillier, F. S. (2000). Introduction to Management Sciences. International ed. New Delhi. McGraw Hill.

[6] Taha, H. A. (2008). Operations Research: An Introduction. New Delhi. Prentice Hall of India Private United.

[7] Customer Experience Leverage Cross-Channel Analytical to Optimize your Customer Dynamics. www.nice.com. Accessedseptember15,2010.

[8] Entrepreneurial Woman Thinking of Starting a Businesses? We can help. www.entreprenuerialwoman.com. Accessed March13,2009.

[9] Kira L. S (2009). Hershey Medical Centre to Open Redesigned Emergency Room. The Patriot-News http://www.pennlive.com/midstate/inde.ssf/html. Accessed 2nd April, 2010.

[10] $\underline{a}_{a} \underline{b} \underline{c} \underline{d} \underline{e} \underline{f} \underline{g}$ Pentiinen A.., Chapter 8 - Queuing System, Lecture Notes: S-38. 145-Introduciton to Teletraffic Theory. Retrieved 2008/25/20.

[11] Gupa, P. K., Hira, D. S. (2005). Problems in Operations Research (Principles and Solutions). New Delhi 110055. S. Chand \& Company Ltd. Ramnagar.

[12] Tijms, H. C. (2008). Algorithmic Analysis of Queues. Chapter 9 in A First Course in Stochastic Models. Wiley, Chichester, 2003.

[13] Winston (2001). Practical Management Science. $2^{\text {nd }}$ ed. Duxbury 511, Forest Lodge Road Pacific Groore C. A. 93950 USA.

[14] Wang, T., Wang U. (2010). "Survey on a Queue Theory Based Handover Scheme for UAVs Communication Network" Chinese Journal of Sensors and Actuators.

[15] Da-Qi, L., Jun-Yi, S. (2007). "Queuing Theory Supervising K. means clustering Algorithan and Its Application in Optimized Design of TTS Network". Journal of Astronautics.

[16] Jing, H., Fang, G., Jim-Hua, S.(2007). Research on the traffic monitoring of the distributed network based on human immune algorithm. Microcomputerinforamtion. Accessed $29^{\text {th }}$ February, 2011. 
[17] Little (2008). Little's Theorem on Queuing http://littles-law.com/tag/queuing-theory. Accessed 2nd June 2012.

[18] Greenshield (2009). Greenshield Theory on Queuing http://www.webl.uidaho.edu./niatt labmanual/chapters/trafficflowtheory/theoryandconcepts/queuingtheory.ht m. Accessed on 5th May 2012.

[19] Bose S. J., (2002). Chapter 1 - An Introduction to Queuing Systems, Kluwer/Plenum Publishers.

[20] Kelly, F. P. (September, 1975). "Networks of Queues with Customers of Different Types". Journal of Applied Probability. 12 No. 3: 542-554

[21] Mayhew, Les, Smith, David (December 2006). Using Queuing Theory to Analyse Completion Times in Accident and emergency departments in the light of the government 4-hour target". Cask Business School. http://www.case.city.ac.uk/media/stories. Retrieved 2008/25/20.

[22] ARPN Journal of Science and Technology. 1 No. 1 November, $2011.2011-2012$ http://www.ejournalofscience.org.

\section{APPENDIX A OGUI ROAD BRANCH}

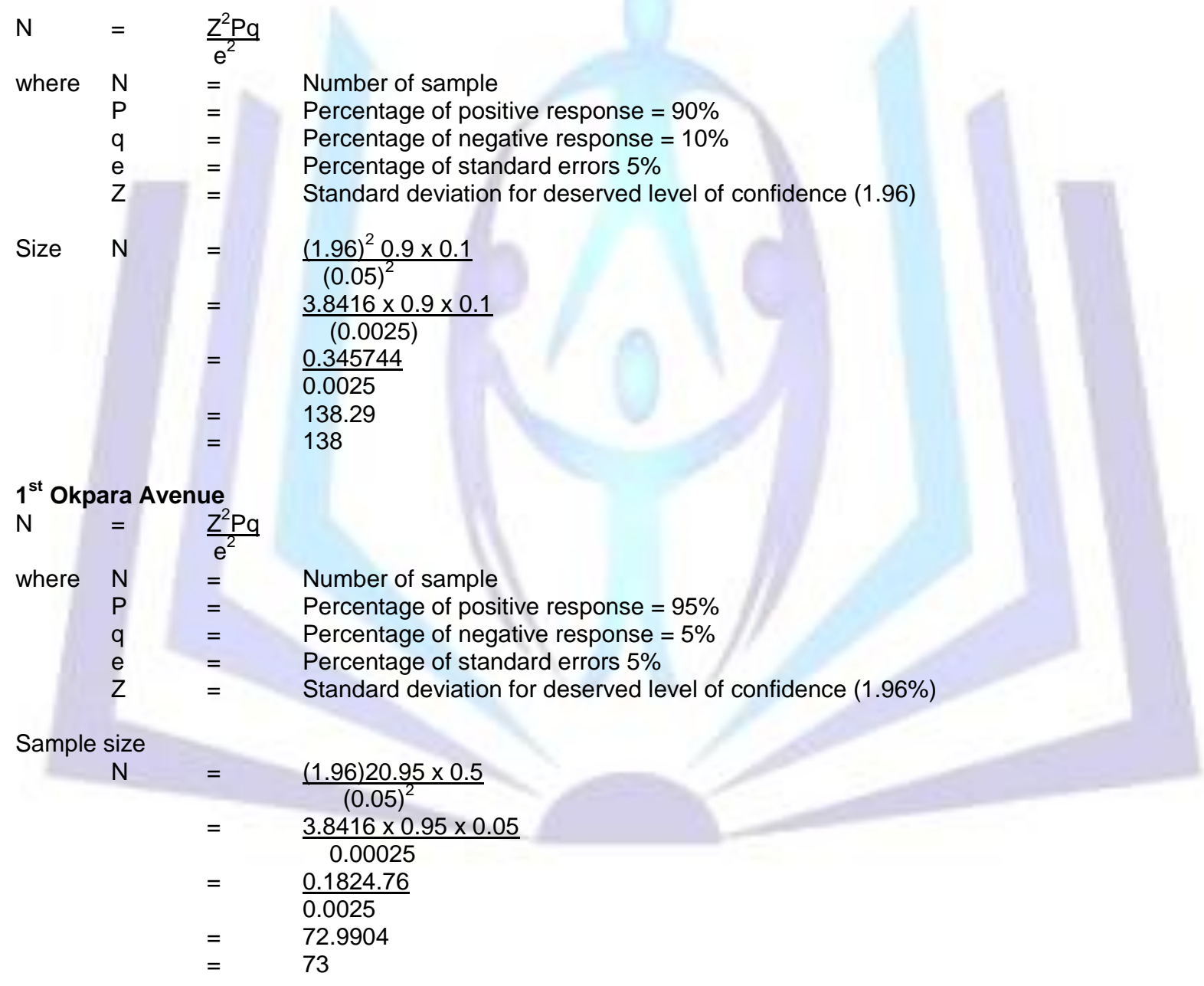

From Ziks Avenue Branch

$\begin{array}{llll}\mathrm{N} & = & \underline{Z^{2} P q} & \\ \text { where } & \mathrm{N} & = & \text { Number of sample } \\ \mathrm{P} & = & \text { Percentage of positive response }=97 \% \\ \mathrm{q} & = & \text { Percentage of negative response }=3 \% \\ \mathrm{e} & = & \text { Percentage of standard errors } 5 \% \\ \mathrm{Z} & = & \text { Standard deviation for deserved level of confidence }(1.96 \%)\end{array}$


Sample Size

$$
\begin{aligned}
N & =\frac{(1.96)^{2} 0.97 \times 0.03}{(0.05)^{2}} \\
& =\frac{3.8416 \times 0.97 \times 0.03}{0.0025} \\
& =44.716 \\
& =
\end{aligned}
$$

\section{Ogbete Market}

$\begin{array}{cll}\mathrm{N} & = & \mathrm{Z}^{2} \\ \text { where } & \mathrm{e} & \mathrm{e}^{2} \\ \mathrm{~N} & = \\ \mathrm{P} & = \\ \mathrm{q} & = \\ \mathrm{e} & = \\ \mathrm{Z} & =\end{array}$

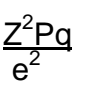

Size $\quad \mathrm{N}=$

\section{Number of sample}

Percentage of positive response $=98 \%$

Percentage of negative response $=2 \%$

Percentage of standard errors 5\%

Standard deviation for deserved level of confidence $(1.96 \%)$

$=\frac{(1.96)^{2} 0.98 \times 0.02}{(0.05)^{2}}$

$=\quad \frac{3.8416 \times 0.98 \times 0.02}{0.0025}$

0.0025

$=\quad 3.07529536$

0.0025

30.11

30

$2^{\text {nd }}$ Okpara Avenue
$\mathrm{N}=\frac{\mathrm{Z}^{2} \mathrm{Pq}}{\mathrm{e}^{2}}$
where $\begin{array}{ll}\mathrm{N} & = \\ \mathrm{P} & = \\ \mathrm{q} & = \\ \mathrm{e} & = \\ \mathrm{Z} & =\end{array}$
Number of sample
Sample Size
$\mathrm{N}$

$=\quad \frac{(1.96)^{2} 0.98 \times 0.02}{0.05^{2}}$
$=\quad \frac{3.8416 \times 0.98 \times 0.02}{0.0025}$
$=\quad \frac{0.07529536}{0.0025}$
$=\quad 30.11$
$=\quad 30$

Percentage of positive response $=98 \%$

Percentage of negative response $=2 \%$

Percentage of standard errors $5 \%$

Standard deviation for deserved level of confidence (1.96\%)

GARDEN AVENUE BRANCH

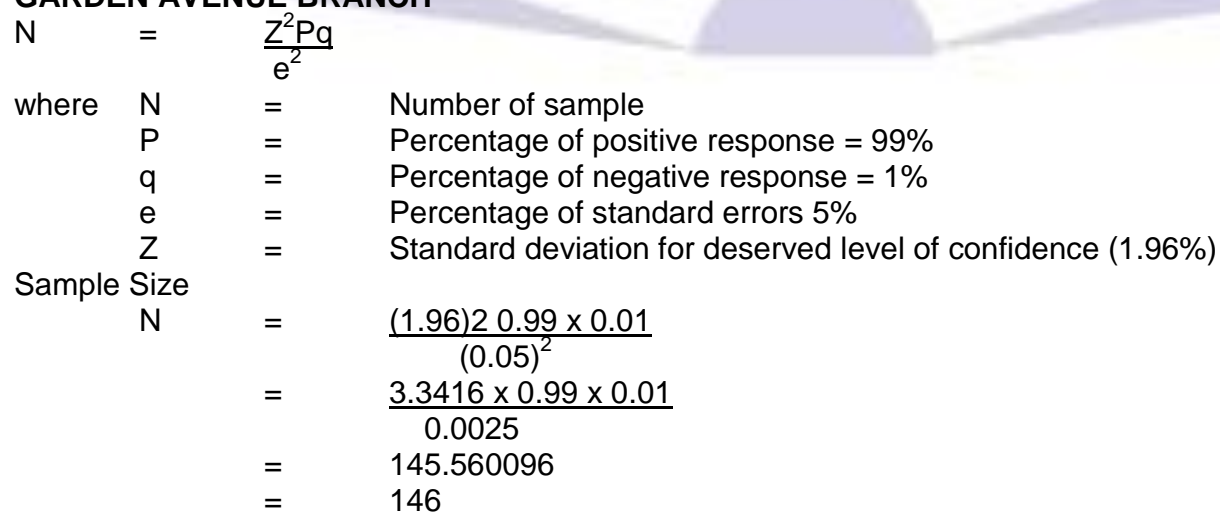

